\title{
Análise técnica e econômica de sistema de extração de toras longas de Tectona grandis com trator arrastador adaptado em floresta plantada
}

\author{
Jhonny Pinto Vieira Mendes Moura ${ }^{1 *}$, Roberto Antonio Ticle de Melo e Sousa ${ }^{1}$, Mariana Peres de Lima Chaves e \\ Carvalho $^{1}$, Rômulo Môra ${ }^{1}$
}

${ }^{1}$ Universidade Federal de Mato Grosso, Rua Fernando Corrêa da Costa, 2367, Boa Esperança, Cuiabá - MT, 78068-600

*Autor para correspondência: mourajpvm@gmail.com

Recebido: Janeiro 2019/ Aceito: Outubro 2019/ Publicado: Dezembro 2019

\section{Resumo}

Neste estudo objetivou-se descrever e analisar os fatores técnicos e econômicos do ciclo operacional do trator arrastador adaptado na atividade de extração de toras longas de Tectona grandis L.f. no sudoeste de Mato Grosso. Foi avaliado o trator arrastador, composto de um trator agrícola Massey Ferguson com uma garra hidráulica acoplada. Utilizou-se o método de cronometragem parcial para registrar os tempos individuais do ciclo operacional. A etapa que mais demandou tempo foi a de viagem de carga, em virtude da desorganização das toras no interior do talhão e, no período chuvoso, pela baixa visualização no interior do talhão; avaliada as interrupções, as pausas mecânicas foram mais frequentes. A disponibilidade mecânica média $(95,75 \%)$ e eficiência operacional média $(87,5 \%)$ foram consideradas altas. A produtividade média $\left(28,95 \mathrm{~m}^{3} \mathrm{cc} / \mathrm{he}\right)$ pode ser explicada pelo tempo e volume extraído individual do ciclo, além de ser inversamente influenciada pela distância de extração. $\mathrm{O}$ custo de produção $\left(\mathrm{R} \$ 2,11 / \mathrm{m}^{3} \mathrm{cc}\right)$ foi considerado baixo em relação às maquinas florestais tradicionais utilizadas para esta mesma atividade. $\mathrm{O}$ custo operacional teve como maiores fatores de composição, os custos com mão de obra e manutenção. Na análise de sensibilidade do custo de produção, a produtividade teve maior influência na variação dos custos. O trator arrastador pode ser uma alternativa ao alto custo de investimento e de operação de equipamentos específicos para a operação, devido ao menor preço de aquisição, operação e manutenção, bem como a versatilidade para outras atividades.

Palavras-chave: Tempo e movimento, Análise operacional, Produtividade florestal.

\footnotetext{
Abstract

This study aimed to describe and analyse the technical and economic factors of the operational cycle of the adapted trawler tractor in the activity of extraction of long logs of Tectona grandis L.f. in the southwest of Mato Grosso. The tractor was composed of a Massey Ferguson agricultural tractor with a hydraulic jaw coupled. The partial timing method was used to record the individual times of the operational cycle. The stage that demanded the most time was the load trip due to the log's disorganization inside the field, and in the rainy period, by the low visualization inside the field; interruptions were evaluated, mechanical pauses were more frequent. The mechanical availability $(95.75 \%)$ and average operating efficiency $(87.5 \%)$ were considered high. The productivity $\left(28.95 \mathrm{~m}^{3} \mathrm{cc} / \mathrm{h}\right)$ can be explained by the time and individual volume extracted from the cycle, in addition to being inversely influenced by the extraction distance. The cost of production $\left(\mathrm{R} \$ 2.11 / \mathrm{m}^{3} \mathrm{cc}\right)$ was considered low in relation to the traditional forest machines used for this same activity. Labor costs and maintenance were the highest composition factors of operating cost. In the sensitivity analysis of the production cost, productivity had a greater
}

influence on the cost variation. The trawler can be an alternative to the high cost of investment and operation of specific equipment for the operation, due to the lower price of acquisition, operation and maintenance, as well as the versatility for other activities.

Keywords: Time and movement, Operational analysis, Forest productivity.

\section{Introdução}

A análise do sistema de colheita florestal envolvendo aspectos técnicos e econômicos conferem ao produtor uma visão ampla do funcionamento da atividade avaliada, podendo assim detectar falhas, gargalos de produções e pontos críticos, onde pode se aplicar as melhorias sugeridas pela avaliação do sistema e, assim, alcançar um sistema de colheita florestal mais produtivo e com possível redução de falhas.

A avaliação técnica das atividades florestais está consolidada dentro das considerações do planejamento, pois ajuda a conhecer, mapear e diagnosticar os processos no que concerne à produtividade, tempo e eficiência.

O estudo econômico dos custos de produção florestal é assunto amplamente debatido e inserido no planejamento das atividades, uma vez que buscar a redução de custo e aumentar a produtividade sem ter queda na qualidade da tora, faz parte de um planejamento complexo que envolve diversos fatores. A operação de extração, dentro do sistema de colheita florestal, com trator arrastador adaptado com garra hidráulica, enfrenta problemas na produção de ordem operacional e mecânica, principalmente, por sofrer com o excesso de carga em virtude de sua adaptação.

Dessa forma, o objetivo deste trabalho foi avaliar os aspectos técnicos e econômicos do ciclo operacional do trator arrastador adaptado na atividade de extração de toras longas de Tectona grandis L.f. no sudoeste de Mato Grosso.

\section{Material e Métodos}

$\mathrm{O}$ estudo foi conduzido em povoamentos de Tectona grandis L. f. de uma empresa no setor florestal, município de Nossa Senhora do Livramento, Mato Grosso. A área de estudo foi definida como a área dos talhões A e B, com 26,1 ha e 26,5 ha, respectivamente, compostos por indivíduos de Teca com idade média de 15 anos.

O sistema de colheita adotado pela empresa é caracterizado como o de toras longas (Malinovski et al., 2008), pois após a equipe de abate realizar o corte raso utilizando motosserra, a árvore de Teca é desgalhada e destopada com o mesmo equipamento no pé do toco e em seguida é conduzida para a esplanada, na margem do talhão, pelo trator arrastador.

O trator agrícola é da marca Massey Ferguson, modelo 5285, ano de fabricação 2004, tração 4x2, com motor à óleo diesel. A garra hidráulica possui duas pinças que são 
movimentadas por pistões hidráulicos, controladas pelo operador.

$\mathrm{Na}$ área de estudo foram mesuradas aleatoriamente 200 árvores que seriam abatidas nos dias seguintes, medindo a Circunferência à Altura do Peito (CAP) utilizando fita métrica e altura total utilizando um hip sômetro haglof. Para o cálculo do volume, utilizou se o fator de forma de 0,5 , mesmo valor utilizado pela empresa. Foram registrados diâmetro médio de $28,91 \mathrm{~cm}$, altura total média de $23,05 \mathrm{~m}$ e volume médio de $0,8516 \mathrm{~m}^{3}$.

A intensidade amostral foi calculada para se conhecer a quantidade de ciclos operacionais necessários e suficientes ao estudo, para isso foi fixado um nível de probabilidade de $95 \%$ de confiança e um limite de erro de $5 \%$. Para o cálculo da intensidade amostral, foi utilizado a metodologia de Barnes (1977), por meio da seguinte equação:

$n \geq \frac{t^{2}+C V^{2}}{E^{2}}$

Em que: $n=$ número mínimo de ciclos operacionais necessários; $t=$ valor tabelado de $\mathrm{t}$ de student, para o nível de probabilidade desejado e graus de liberdade (número total de amostras menos um); $C V=$ coeficiente de variação em porcentagem; e $E=$ erro admissível, em porcentagem.

\section{Avaliação técnica do estudo de tempo e movimento}

Para avaliar o tempo de trabalho total e médio, produtividade, eficiência e disponibilidade mecânica do trator arrastador, foram coletados os tempos de cada etapa envolvido no arraste de toras longas de teca, do local de corte até à esplanada. $\mathrm{O}$ registro dos dados de tempos dos ciclos operacionais foi efetuado pelo método de cronometragem de tempos parciais. Stöhr (1978) classifica o método de tempo parcial como a medição de cada atividade parcial individualmente, com detenção do cronômetro ao final da mesma.

Foram utilizados dois cronômetros, um para registrar o tempo total do ciclo, e outro para registrar o processo parcial atual dentro do ciclo. No caso de o ciclo apresentar interrupção, foi anotado o tempo e a motivação da interrupção para posterior classificação e avaliação.

As distâncias de arraste foram demarcadas em 20 metros (d1), entre 20 e 40 metros (d2), entre 40 e 60 metros (d3) e acima de 60 metros (d4).

O ciclo operacional do trator arrastador é composto das seguintes etapas: Viagem sem carga (VSC): etapa que se inicia com a entrada dos pneus dianteiros do trator arrastador dentro do talhão e termina quando o trator se posiciona próximo à primeira tora a ser carregada e abre a garra hidráulica; Viagem de carga (VDC): inicia-se quando a garra prende a primeira tora e logo após o operador decide se haverá uma, duas, três ou mais toras na garra com base nas dimensões, na distância das toras entre si e possíveis obstáculos. Este processo termina no instante que o operador eleva a (s) tora (s) com a garra hidráulica do solo após ter terminado o processo decisivo da quantidade de toras a serem carregadas; Viagem com carga (VCC): começa quando o trator arrastador se movimenta após o carregamento ser realizado e termina quando o trator arrastador se encontra na esplanada, na margem do talhão; Descarregamento (DES): inicia-se quando o trator arrastador está na esplanada e abre a garra hidráulica, logo após se movimenta para realizar a manobra na estrada com finalidade de se posicionar em direção ao talhão novamente. Este processo termina quando as rodas dianteiras estão posicionadas no interior do talhão, finalizando o ciclo; Interrupções (INT): ocorrem quando paradas foram necessárias enquanto um dos processos estava ocorrendo. As interrupções foram divididas em mecânicas e não mecânicas. As interrupções não mecânicas têm subdivisões de: pausa fisiológicas, solução operacional, problema operacional e organização da pilha de madeira na beira do talhão. As Interrupções mecânicas estão compreendidas as manutenções, ajustes e reparos do trator ou da garra hidráulica.

Neste trabalho a hora efetiva (he) é considerada como o tempo individual do ciclo utilizado para realizar todas as etapas do ciclo operacional, sem considerar as interrupções. Podendo esta ser somada às outras horas efetivas para compor o tempo total de trabalho efetivo.

Para avaliar a produtividade efetiva do trator arrastador, foi utilizada a expressão sugerida por Minette et al. (2008).

Pre $=\frac{N \times V}{h e}$

Em que: Pre $=$ produtividade efetiva $\left(\mathrm{m}^{3} \mathrm{cc} \cdot \mathrm{he}^{-1}\right) ; N=$ número total de árvores extraídas; $V=$ volume médio porárvore com casca $\left(\mathrm{m}^{3} \mathrm{cc}\right)$ e; $h e=$ horas efetivas de trabalho.

A disponibilidade mecânica foi aferida a partir da seguinte expressão:

$D M=\frac{T E}{(T E+T M)} x 100$

Em que: $D M=$ disponibilidade mecânica $(\%) ; T E=$ tempo total de trabalho efetivo (horas); e $T M=$ tempo de manutenção (horas).

Já a eficiência operacional foi obtida a partir da seguinte expressão:

$E O=\frac{T E}{(T E+T P)} \times 100$

Em que: $E O=$ eficiência operacional $(\%) ; T E=$ tempo total de trabalho efetivo (horas); e $T P=$ tempo de interrupções (horas).

\section{Análise econômica}

A metodologia utilizada na análise econômica da atividade de extração realizada pelo trator arrastador foi adaptada da metodologia descrita por Miyata (1980) e Valverde (1995) ao incorporar os custos de administração aos cálculos. Assim, como em Minette et al. (2008), neste estudo os custos foram divididos em custos fixos, variáveis e administrativos, expressos em reais por hora efetiva de trabalho $(\mathrm{R} \$ / \mathrm{he})$

Será avaliado, como um só, o conjunto que compõe o trator arrastador, o trator agrícola como máquina base e a garra hidráulica acoplada ao mesmo. Sendo considerado o valor residual do trator arrastador de $10 \%$ do valor de aquisição.

Os custos fixos que, periodicamente, oneram a empresa, não tendo relação com a atividade da máquina e são subdivididos em depreciação, e juros e seguros.

A depreciação é definida como um cálculo que registra a perda de valor da máquina, no decorrer da sua vida útil, devido a desgastes, avarias e defasagem. Para o cálculo da depreciação, foi utilizado o método da depreciação linear: $D p: \frac{V a-V r-V p n}{V u * h e a}$

Em que: $D p=$ depreciação linear da máquina $(\mathrm{R} \$ / \mathrm{he}) ; V a=$ valor de aquisição da máquina (R\$); $V r=$ valor residual da máquina (\%); Vpn = valor de um jogo de pneus (R\$); $V u=$ vida útil estimada (anos); e hea = horas efetivas de uso anual.

Neste estudo foi utilizado uma taxa de juros real de $6,9 \%$ a. a. (ao ano), taxa SELIC para o período de janeiro de 2018, onde a mesma foi aplicada ao investimento médio anual (IMA) para realizar o cálculo dos juros. Os seguros são compreendidos os custos incorridos do uso e posse da máquina e também em virtude das avarias a que estão expostas as máquinas no ambiente de trabalho. A taxa de seguros utilizada foi de $4,5 \%$ a.a.. O cálculo pode ser descrito da seguinte forma:

$S=\frac{I M A * i}{h e}$ 
Em que: $S=$ custos com juros e seguros (R $\$ / h e) ; i=$ taxa de juros e de seguros anuais simples $(\%)$; $h e=$ horas efetivas de uso anual; e $I M A=$ investimento médio anual $(\mathrm{R} \$)$.

$I M A=\frac{(V a-V r) *(V u+1)}{2 * V u}+V r$

Em que: $V a=$ valor de aquisição da máquina $(\mathrm{R} \$) ; V r=$ valor residual da máquina (\%); e $V u=$ vida útil estimada (anos). Os custos variáveis são os que variam conforme a quantidade produzida pela máquina ou com o seu uso. Tais custos dependem do nível da atividade por período avaliado. Estes custos estão inseridos os custos com combustíveis, lubrificantes, óleo hidráulico, pneus, remuneração do operador, manutenção da máquina, materiais diretos e materiais auxiliares. Todos os custos e informações de consumo foram fornecidos pela empresa.

De forma que o custo com manutenção e reparos é referente as manutenções e reparos mecânicos na máquina em face das prováveis avarias no decorrer da sua vida útil.

Os custos de mão de obra são relacionados ao salário do operador mais os custos de benefícios e encargos sociais, como $13^{\circ}$ salário, férias, seguro, treinamentos, alimentação, vestuário, seguros, contribuições sociais, etc., que foram obtidos na empresa em valores mensais e divididos pela quantidade de horas trabalhadas por mês.

Já os custos de administração são relacionados aos trabalhos de escritório e supervisão das atividades de extração com o trator arrastador. O custo de administração, para este estudo, foi considerado, junto da administração da empresa, como $6 \%$ do custo parcial e pode ser calculado conforme a expressão:

$C A D=(C F+C V) * k$

Em que: $C A D=$ Custo de administração (R $\$ / h e) ; C F=$ Custo fixo total (R\$/he); $C V=$ Custo variável total $(\mathrm{R} \$ / \mathrm{he})$; e $k=$ coeficiente de administração (\%).

O custo operacional total é a soma dos custos fixos, variáveis e de administração envolvidos na atividade de extração pelo trator arrastador, sendo expressa pela seguinte equação:

$C O T=C F+C V+C A D$

Em que: $C O T=$ custo operacional total $(\mathrm{R} \$ / \mathrm{he}) ; C F=$ custos fixos $(\mathrm{R} \$ / \mathrm{he}) ; C V=$ custos variáveis $(\mathrm{R} \$ / \mathrm{he})$; e $C A D=$ custos de administração ( $\mathrm{R} \$ /$ he).

O custo de produção do trator arrastador foi obtido a partir da razão entre os custos operacionais totais e a produtividade, sendo expressa pela seguinte equação:

$C P=\frac{C O T}{P r o d}$

Em que: $C P=$ custo de produção $\left(\mathrm{R} \$ / \mathrm{m}^{3} \mathrm{cc}\right) ; C O T=$ custo operacional total $(\mathrm{R} \$ / \mathrm{he})$; e $\operatorname{Prod}=$ produtividade do trator arrastador $\left(\mathrm{m}^{3} \mathrm{cc} / \mathrm{he}\right)$.

\section{Análise de sensibilidade dos custos de produção}

A análise de sensibilidade dos custos de produção tem como finalidade determinar o nível de variação dos resultados financeiros diante de alterações nas variáveis mais relevantes de um determinado projeto ou análise econômica (Oliveira, 2009).

Para a análise de sensibilidade serão utilizadas as variáveis que mais influenciaram nos custos de produção, em percentuais. Então, tais variáveis serão submetidas a uma variação de $60 \%$ (30\% para mais e para menos), com intenção de captar o maior intervalo de variação dos respectivos custos, para posteriormente analisar a influência dessas variáveis na variação do custo de produção do trator arrastador.

\section{Procedimentos estatísticos}

Os dados foram tratados no programa estatístico $\mathrm{R}(\mathrm{R}$ Development Core Team). As variáveis de tempo individual de ciclo, volume e produtividade foram tabuladas com o objetivo de aplicar os testes estatísticos adequados. As distâncias de extração, foram consideradas como tratamento. Após o teste estatístico de Shapiro-Wilk, foi verificado que o conjunto de dados para o tempo efetivo individual dos ciclos e para a produtividades não apresentaram distribuição normal, com p-valor igual a zero. Como alternativa para a análise de variância paramétrica, de forma que seus pressupostos não foram atendidos, optou-se por utilizar testes não paramétricos para amostras independentes.

Para conjuntos de dados com três ou mais tratamentos, o teste não paramétrico utilizado foi o de Kruskal-Wallis. Em todos os cálculos foi considerado $\alpha 5 \%$.

Para conjuntos de dados em que os tratamentos diferem entre si no teste não paramétrico de Kruskal-Wallis e foi necessário diferenciar os tratamentos, foi utilizado o teste de Dunn para comparações múltip las, considerando $\alpha 5 \%$.

Ademais, foi realizada no software $R$ Project uma análise de regressão linear múltipla para verificar a relação entre a variável dependente produtividade e variáveis independentes, que foram selecionadas a partir da seleção automática pelo método de stepwise configurado para analisar nas direções forward/backward, considerando $\alpha 5 \%$. Este procedimento foi realizado no programa computacional R (R Development Core Team).

Foram submetidas à seleção stepwise as variáveis independentes volume individual do ciclo em metros cúbicos com casca (VI), número de toras por ciclo (NT), tempo efetivo individual do ciclo em horas (TI) e distância de extração do ciclo em metros (DE). A equação ajustada foi selecionada automaticamente pelo software por meio do critério de informação de Akaike (AIC).

Para a estimativa da produtividade do trator arrastador foram selecionadas as variáveis independentes que compõem o modelo a seguir:

Prod $=a+b V I+c T I$

Em que: Prod $=$ produtividade efetiva do trator arrastador $\left(\mathrm{m}^{3} \mathrm{cc} / \mathrm{he}\right) ; V I=$ volume individual do ciclo $\left(\mathrm{m}^{3} \mathrm{cc}\right) ; T I=$ tempo efetivo individual do ciclo (he); e; $a, b$, e $c=$ parâmetros de ajuste do modelo.

\section{Resultados e discussão Análise técnica}

Para a amostragem piloto, realizado no primeiro dia de coleta de dados, foram levantados 144 ciclos e após cálculo de intensidade amostral, 24 ciclos seriam suficientes para a realização do estudo.

Em 10 dias de trabalho, 759 ciclos operacionais foram registrados, atendendo assim à intensidade amostral do estudo. Foram extraídas 1.586 toras longas. O tempo médio gasto para se completar o ciclo operacional foi de $03 \min 59 \mathrm{~s}$, sendo o tempo máximo de $16 \min 55$ s e o mínimo de $0 \min 11$ s, com coeficiente de variação de $51,98 \%$.

A distribuição dos tempos médios percentuais de cada etapa da atividade de extração na área de estudo (Figura 1) demonstra que a viagem de carga ocupa o maior tempo médio, seguido da viagem sem carga e viagem com carga. 


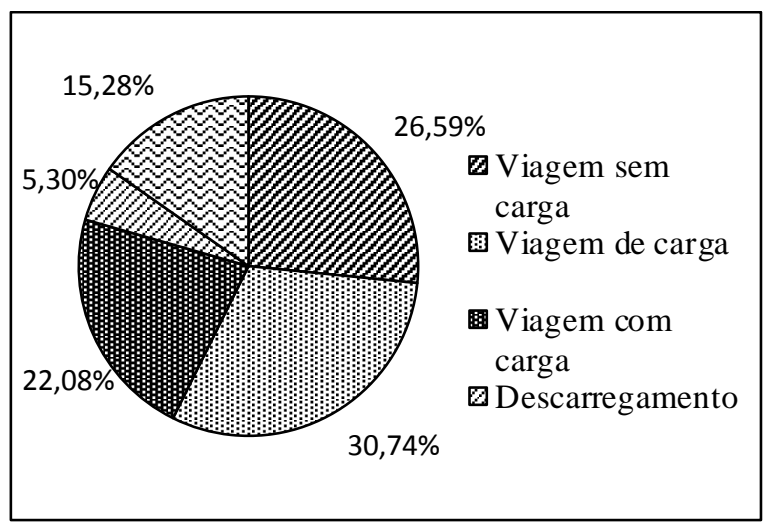

Figura 1. Distribuição percentual do tempo médio para o ciclo operacional do trator arrastador na extração de toras longas de teca no sudoeste de mato grosso, 2016-2017.

A atividade anterior à extração é a de corte, onde as árvores após o corte, desgalhamento e destopamento não são mantidas organizadas ou seguindo uma única direção no interior do talhão, o que confere à atividade de extração, especificamente na etapa de viagem de carga, maior tempo para compor a carga e atingir a capacidade máxima do equip amento.

No período chuvoso o desenvolvimento da brotação é intenso e em poucos meses a Teca, no povoamento, domina o sub-bosque e dificulta a visualização de árvores abatidas no interior do talhão, levando o operador do trator arrastador a demorar mais tempo para identificar as árvores no solo, dessa forma a viagem de carga demanda mais tempo, ocupando $30,74 \%$ do tempo médio do ciclo operacional.

A distribuição percentual do tempo total das interrupções registradas (Figura 2), evidencia que a pausa mecânica demandou maior tempo e a maior parte foi devido a problemas mecânicos pontuais, tais como câmbio travado e mangueira do sistema hidráulico da garra desacoplada ou danificada.

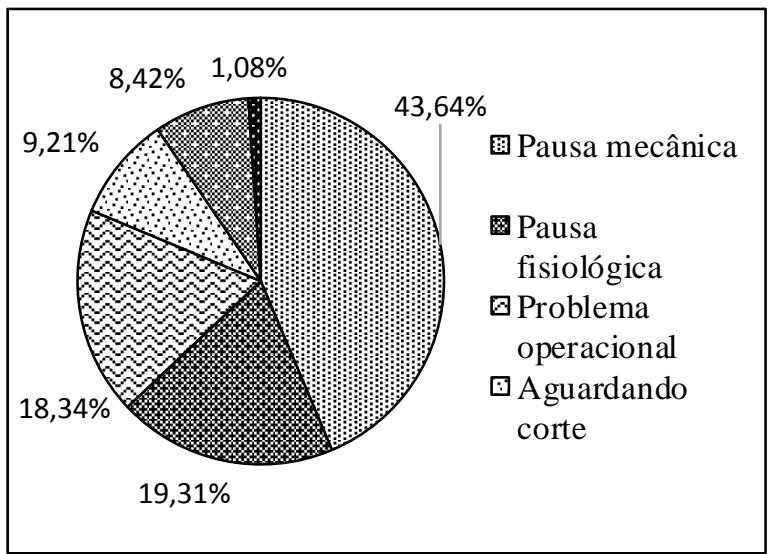

Figura 2. Distribuição percentual de tempo médio das interrupções para o ciclo operacional do trator arrastador na extração de toras longas de teca no sudoeste de mato grosso, 2016-2017.

Quando 43,64\% das interrupções registradas são de ordem mecânica, que ocorreram justamente por falta de manutenção preventiva e corretiva mais eficiente, indicam necessidade de planejamento para prevenção de falhas mecânicas. Ao avaliar um trator florestal clambunk skidder, Santos et al. (2013) registraram que as interrupções mecânicas ocupavam $11,41 \%$ do tempo total do ciclo operacional, menor do que o encontrado neste estudo, assim, evidenciando que o trator aqui estudado por ser constituído de uma adaptação, possui maior necessidade de pausas para intervenções mecânicas que um trator florestal construído com finalidade de extração.

A subdivisão "aguardando corte" ocupa 9,21\% das interrupções totais e tem origem na falta de toras no interior do talhão, sendo assim, necessário aguardar a equipe de corte realizar a sua atividade para disponibilizar novas unidades de toras no interior do talhão.

As etapas do ciclo operacional de viagem sem carga, de viagem de carga e de viagem com carga foram influenciadas pela distância de extração (Figura 3), diretamente no tempo de realização do ciclo operacional. Sendo a mesma situação encontrada por Lopes et al. (2007) ao avaliarem Skidders de esteira e de pneus. Porém, a etapa de descarregamento não foi alterada, pois esta era realizada na esplanada e os movimentos observados realizados pelo trator arrastador eram similares, independentemente da distância em que a(s) tora(s) era(m) extraídas.

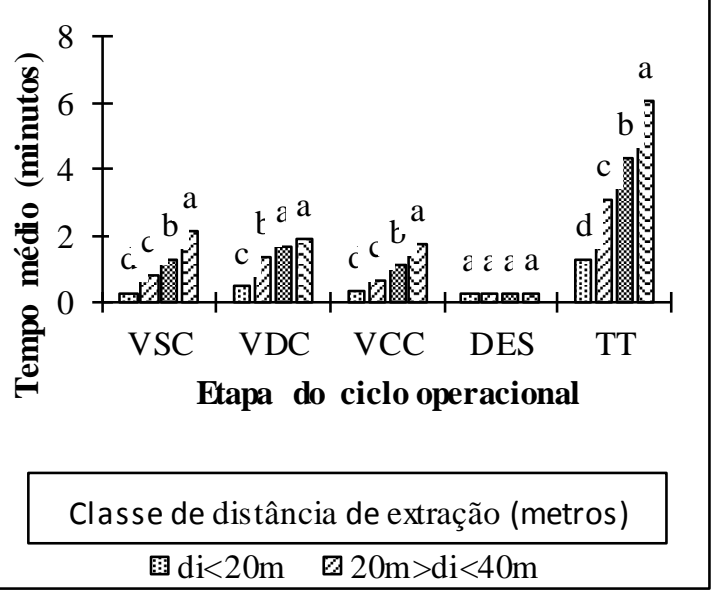

Figura 3. Tempos médios de duração das etapas do ciclo operacional do trator arrastador nas diferentes classes de distância de extração na atividade de extração de toras longas no sudoeste de mato grosso, 2016-2017. Em que: di: Distância de extração, VSC: Viagem sem carga, VDC: Viagem de carga, VCC: Viagem com carga, DES: Descarregamento e TT: Tempo total efetivo; barras seguidas pela mesma letra não diferem entre si pelo teste de comparações múltiplas de Dunn ao nível de $5 \%$ de probabilidade.

A disponibilidade mecânica média registrada foi de $95,75 \%$, sendo este, valor maior que os encontrados por Fiedler et al. (2008), que avaliaram um sistema de colheita de toras longas de eucalipto, o skidder apresentou disponibilidade mecânica média de 90,9\%.

A eficiência operacional que infere sobre o tempo efetivo em relação ao tempo total utilizado, em média foi de $87,5 \%$. Valor maior que o encontrado por Cechin (2000), 77,1\%, em avaliação de trator arrastador na extração de eucalipto. Fiedler et al. (2008) encontraram, também, menor eficiência avaliando skidder em extração de eucalipto, com valor médio de $73,2 \%$. A eficiência operacional do trator arrastador, neste estudo, pode ser considerada satisfatória, porém é importante reduzir as interrupções, principalmente as mecânicas.

Foi registrado volume total de $1.145,42 \mathrm{~m}^{3} \mathrm{cc}$ (metro cúbico com casca) para os 759 ciclos operacionais avaliados. Aliado ao tempo efetivo (he) registrado pelo trator arrastador, foi possível obter a produtividade média por hora efetiva de $28,95 \mathrm{~m}^{3} \mathrm{cc} / \mathrm{he}$, já Santos et al. (2013) registraram produtividade média de $80,25 \mathrm{~m}^{3} \mathrm{cc} /$ he para o trator florestal arrastador clambunk skidder e Fiedler et al. (2008) ao 
avaliarem um skidder dentro de um sistema de exploração, registraram produtividade de $42,3 \mathrm{~m}^{3} \mathrm{cc} / \mathrm{he}$. Ambos casos denotam a menor produtividade do trator adaptado em estudo em face de máquinas florestais de arraste.

A produtividade do trator arrastador é influenciada pela distância (Figura 4), pois quanto maior a distância, menor a produtividade, bem como, quanto maior a produtividade, menor o tempo gasto para realizar o ciclo. Semelhante ao estudo de Santos et al. (2013), que avaliaram a produtividade de um Skidder Clambunk, onde a distância influenciou em $71 \%$ na variação da produtividade.

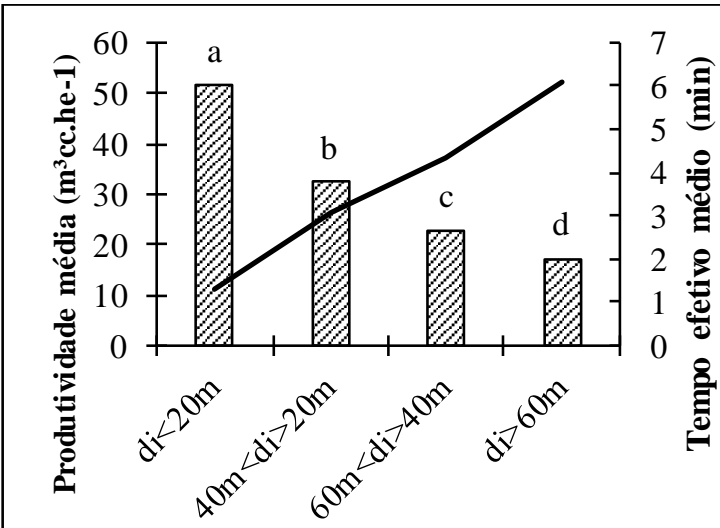

Classes de distância de extração

\section{שa Produtividade $\longrightarrow$ Tempo}

Figura 4. Produtividades médias para as classes de distância para análise de produtividade do trator arrastador na extração de toras longas de teca no sudoeste de mato grosso, 2016-2017. Em que: di: distância de; barras seguidas pela mesma letra não diferem entre si pelo teste de comparações múltiplas de Dunn ao nível de 5\% de probabilidade.

A maior produtividade, dentre as classes de extração, é pertencente à faixa de distância de até 20 metros com 51,56 $\mathrm{m}^{3} \mathrm{cc} /$ he. Lopes et al. (2007) encontraram situação semelhante ao avaliar a produtividade de skidders, onde a maior produtividade se manteve nas faixas iniciais de distância avaliada, porém com produtividade superior, cerca de 200 $\mathrm{m}^{3} \mathrm{cc} \cdot \mathrm{he}^{-1}$.

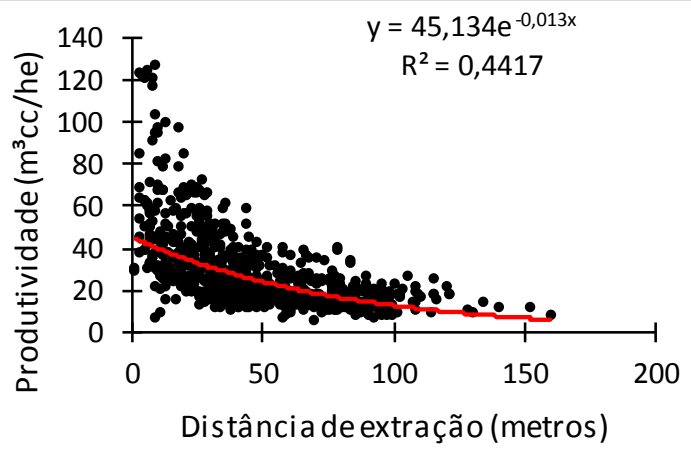

Figura 5. Variação da produtividade do trator arrastador em relação à distância de extração na atividade de extração de toras longas no sudoeste de mato grosso, 2016-2017. Em que: linha contínua $=$ linha de tendência exponencial.

Assim, como o tempo médio efetivo do ciclo operacional, a produtividade também apresentou variação alta, o que é normal para a atividade, em virtude da natureza de operação do trator arrastador, pois este pode realizar o arraste em distâncias de extração completamente distintas. Dessa forma, a produtividade do trator arrastador é influenciada pela distância de extração, explicando $44 \%$ de sua variabilidade (Figura 5), sendo esta, também, a variável de maior inferência na produtividade. Para Lopes et al. (2007), que avaliaram skidders com diferentes tipos de rodados, a produtividade média é também diretamente influenciada pela distância de extração, pois apresenta decréscimo devido ao incremento de tempo do ciclo operacional.

As variáveis independentes selecionadas para compor o modelo da análise, explicaram $62,2 \%$ da variação da produtividade do trator arrastador, com um erro padrão percentual da estimativa de 10,93\%. Oliveira (2013) encontrou coeficiente de determinação maior, sendo que no modelo estudado pelos autores, a variável distância de extração foi adicionada.

Prod $=37,47-486.93 T I+15,68 \mathrm{VI}$

m que: Prod $=$ produtividade efetiva estimada $\left(\mathrm{m}^{3} \mathrm{cc} / \mathrm{he}\right) ; T I$ $=$ tempo efetivo individual do ciclo (he); e $V I=$ volume individual do ciclo $\left(\mathrm{m}^{3} \mathrm{cc}\right)$.

Com a aplicação do modelo encontrado, é possível observar que com o aumento do volume extraído e diminuição do tempo do ciclo operacional, a produtividade do trator arrastador aumenta proporcionalmente, mais evidente na faixa com menor distância de extração.

\section{Análise econômica}

Considerando uma taxa de juros de $14,15 \%$ a.a. e eficiência operacional média de $87,5 \%$, foi possível obter o custo operacional por hora efetiva de trabalho de $\mathrm{R} \$ 61,16 /$ he, este valor associado à produtividade média do trator arrastador por hora efetiva de trabalho, chegou se ao custo de produção de $\mathrm{R} \$ 2,11 / \mathrm{m}^{3} \mathrm{cc}$.

Os custos variáveis representam 49,8\% do custo operacional total (Figura 6), que é composto principalmente pelos custos de manutenção e reparo ( $\mathrm{R} \$ 9,90 / \mathrm{he}$ ) e de combustível (R $\$ 8,55 /$ he). Já o custo fixo, representando $19,8 \%$ do custo operacional total, tem em sua composição os custos de juros (R \$ 5,32/he) e de depreciação (R \$ 5,10/he) representando, juntos, $86 \%$ dos custos fixos.

Os custos com manutenção em reparos ocupam a maior fatia dos custos variáveis $(32,5 \%)$ e isso é explicado pelas constantes pausas mecânicas e reposição de peças durante o trabalho.

O combustível ocupa 28\% dos custos variáveis e é explicado pelo fato da atividade ser realizada de forma ativa e em alta rotação com constantes trocas de marcha. Conforme Fernandes e Leite (2001), o consumo de combustível corresponde a um dos principais fatores de composição do custo operacional da máquina, situação observado neste estudo, sendo o custo com combustível o terceiro maior custo dentro do custo operacional total.

Os juros e a depreciação corresponderam a $43,9 \%$ e $42,11 \%$ do custo fixo, respectivamente.

$\mathrm{O}$ custo médio de produção do trator arrastador é de $\mathrm{R} \$$ $2,11 / \mathrm{m}^{3} \mathrm{cc}$ (reais por metro cúbico com casca), valor abaixo do encontrado por Oliveira (2013) que registrou $\mathrm{R} \$$ $2,36 / \mathrm{m}^{3} \mathrm{cc}$

O custo produção, assim como a produtividade do trator arrastador, foram influenciados pela distância de extração, porém tem comportamento inverso (Figura 7).

O comportamento oposto entre a produtividade e custos totais de produção do trator arrastador, em relação às distancias de extração, confere à atividade a necessidade de estratégias de minimização dos tempos ineficientes e de melhor aproveitamento do tempo efetivo da máquina, com o 
objetivo de compensar o maior custo de produção dos ciclos operacionais nas maiores distâncias de extração

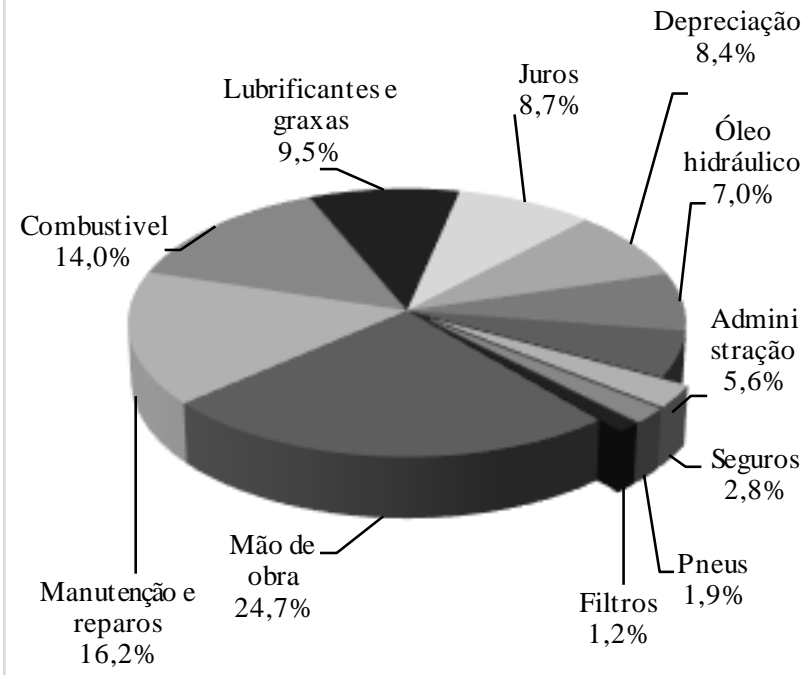

Figura 6. Distribuição percentual dos componentes do custo operacional total do trator arrastador na atividade de extração de toras longas no sudoeste de mato grosso, 2016-2017.

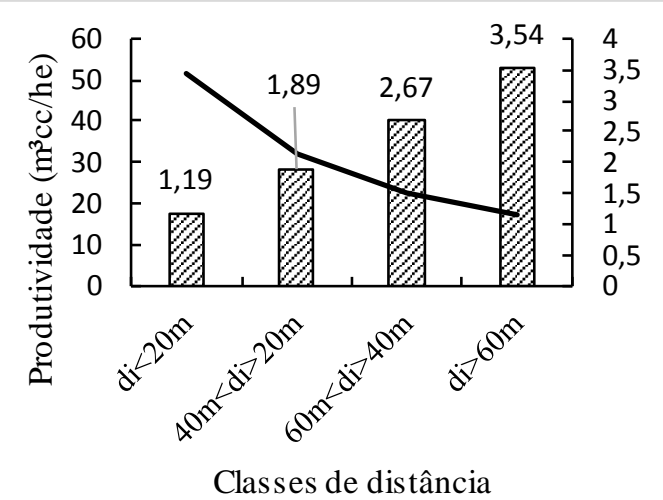

ש\%ׁ Custo de produção — Produtividade

Figura 7. Custo de produção e produtividade do trator arrastador em função das classes de distância de extração na atividade de extração de toras longas no sudoeste de mato grosso, 2016-2017. Em que: di: distância de extração.

\section{Análise de sensibilidade dos custos}

Dentre os fatores que compõem os custos totais de produção do trator arrastador, os que mais influenciaram foram os custos com a manutenção, o combustível, a produtividade efetiva média e a mão de obra. Tais custos foram submetidos à uma variação de 60\% (30\% para mais e para menos), exceto o custo com combustível, pois este por mais que contribua para a formação do custo de produção, constitui indicativo de eficiência do sistema de conversão de energia para o trator, sendo assim, indispensável à atividade, portanto, irrelevante para a análise de sensibilidade.

$\mathrm{Na}$ análise econômica de sensibilidade para o trator arrastador (Figura 8), partindo de um valor de $R \$ 2,09 / \mathrm{m}^{3} \mathrm{cc}$, o custo de produção apresentou valor de $\mathrm{R} \$ 1,63 / \mathrm{m}^{3} \mathrm{cc}$ quando a produtividade aumentou em $30 \%$, sendo este o menor valor da análise. Porém quando se diminui a produtividade em $30 \%$, o custo de produção chega a um valor de $\mathrm{R} \$ 3,02 / \mathrm{m}^{3} \mathrm{cc}$, ou seja, aumentando o custo de produção em $30,79 \%$ comparado com o determinado.

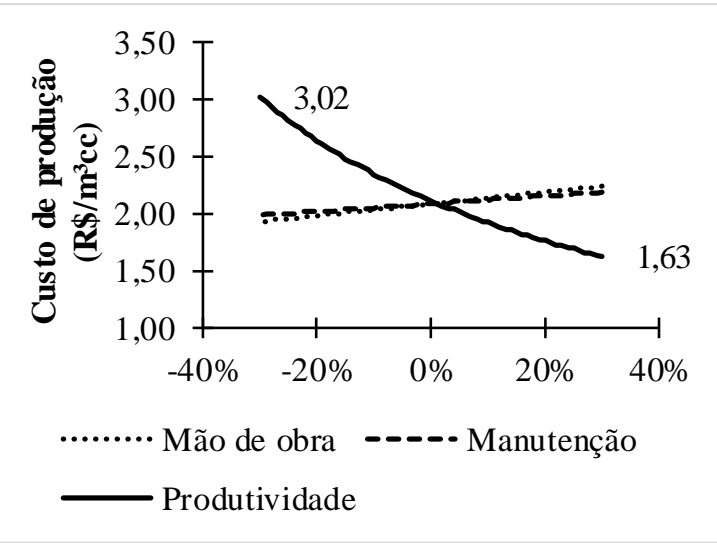

Figura 8. Variação do custo de produção do trator arrastador em função da produtividade, custo de mão de obra e custo de manutenção na atividade de extração de toras longas no sudoeste de mato grosso, 2016-2017.

Variando os custos de manutenção e mão de obra, constata-se que existe alteração no custo de produção, porém quase não houve diferença entre a sensibilidade motivada pela variação com estes custos.

O intervalo entre valor máximo e valor mínimo do custo de produção variando para os custos de manutenção e de mão de obra não apresentam grande diferença de valores, sendo a maior diferença observada nos valores para variação com a produtividade, sendo este o fator que mais tem influência no custo de produção.

\section{Conclusões}

Diante do proposto neste trabalho, pode se concluir que a etapa que mais demandou tempo médio foi a de viagem de carga, em virtude do tempo gasto para procurar as toras no interior do talhão, devido à intensa regeneração natural no período chuvoso e; pela dispersão desorganizada das toras no interior do talhão em virtude de falha na atividade anterior.

O registro das interrupções apresentou em sua maior parte pausas mecânicas, seguido de pausas fisiológicas e problemas operacionais.

A disponibilidade mecânica e eficiência operacional do trator arrastador são consideradas alta.

A produtividade do trator arrastador pode ser explicada pelo tempo e volume individual do ciclo, e é influenciada pela distância de extração.

A maior produtividade e maior aproveitamento do tempo estão concentradas nas atividades que são realizadas mais próximas da esplanada, com menores distâncias.

$\mathrm{Na}$ análise econômica a operação do trator arrastador é considerada de baixo custo se comparada às máquinas florestais que normalmente são utilizadas para esta atividade, considerando que a máquina aqui avaliada é uma adaptação alternativa.

\section{Referências}

Barnes RM (1977) Estudo de movimentos e de tempos: projeto e medida de trabalho. Tradução de $6^{\mathrm{a}}$ Ed. São Paulo: Edgard Blücher, 635p.

Stöhr GWD (1978) Importância e aplicação do estudo do trabalho. In: Curso De Atualização Sobre Sistemas De Exploração E Transporte Florestal, Curitiba, Brasil. 
Miy ata OP (1980) Custo operacional de máquinas utilizadas na exploração e transporte da cultura do eucalipto. Informe Agropecuário. Belo Horizonte, 14: 4-30.

Valverde SR (1995) Análise técnica e econômica do subsistema de colheita de árvores inteiras em povoamentos de eucalipto. Dissertação, Universidade Federal de Viçosa. $123 \mathrm{p}$.

Cechin FN (2000) Análise da eficiência e do desempenho operacional das máquinas e dos equipamentos utilizados no corte raso de povoamentos florestais na região do planalto norte de Santa Catarina. Dissertação, Universidade Federal do Paraná. 136 p.

Fernandes HC, Leite AMP (2001) Proposta de uma metodologia para ensaio de máquinas colhedoras de madeira. In: Simpósio Brasileiro sobre Colheita Florestal, Porto Seguro, Brasil.

Lopes ES, Missel JWP, Dias AN, Fiedler NC (2007) Avaliação técnica do trator florestal arrastador "Skidder" com diferentes tipos de rodados na extração de madeira em povoamentos de Pinus. Revista Árvore, 31(6): 1053-1061.

Lopes SE (2007) Análise técnica e econômica de um sistema de colheita florestal. Tese, Universidade Federal de Viçosa. $124 \mathrm{p}$.

Fiedler NC, Rocha EB, Lopes ES (2008) Análise da produtividade de um sistema de colheita de árvores inteiras no norte do estado de Goiás. Floresta, 38(4): 577-586.

Malinovski JR, Camargo CMS, Malinovski RA, Malinovski RA (2008) Sistemas. In: Colheita Florestal. $2^{a}$ Ed. 501p.

Minette LJ, Silva EM, Freitas KE, Souza AP, Silva EP (2008) Análise técnica e econômica da colheita florestal mecanizada em Niquelândia, Goiás. Revista Brasileira de Engenharia Agrícola e Ambiental, 12(6): 659-665.

Oliveira RJ (2009) Avaliação econômica da utilização de cabos aéreos na colheita florestal em regiões montanhosas. Dissertação, Universidade Federal de Viçosa. 54p.

Oliveira D (2013) Análise operacional e custos de colheita de madeira em povoamentos de eucalipto. Dissertação, UNICENTRO. 101p.

Santos PHA, Souza AP, Marzano FLC, Minette LJ (2013) Produtividade e custos de extração de madeira de eucalipto com clambunk skidder. Revista Árvore, 37(3): 511-518. 